\title{
CONVENCIÓ I EXCEPCIÓ EN LA IMATGE DELS GRAVATS DE RAMON LLULL
}

\author{
CONVENTION AND EXCEPTION IN THE IMAGE OF THE ENGRAVINGS \\ OF RAMON LLULL.
}

Miquela Sacarès Taberner

Universitat de les Illes Balears

ABSTRACT: Study of the engravings that depict Ramón Llull, which are found mainly in Lullian editions from the sixteenth to the nineteenth centuries. This study first analyzes the conventional images that define the conceptual iconographic type of Llull. It also examines two engravings whose meaning is related to the context of the period.

KEYWORDS: Ramon Llull; Francesc Rossello; Lullian editions; Lullian iconography.

RESUMEN: Estudio de los grabados que representan a Ramón Llull, localizados en las ediciones lulianas entre los siglos XVI al XIX. En primer lugar se analizan las imágenes que definen el tipo iconográfico conceptual de Llull. En segundo lugar, dos grabados cuyo significado és interpretado en relación con el contexto de la época.

PALABRAS CLAVES: Ramon Llull; Francesc Rosselló; ediciones lul·lianes; iconografía luliana.

RESUM: Estudi dels gravats que representen Ramon Llull, localitzats en les edicions lullianes entre els segles XVI al XIX. En primer lloc s'analitzen les imatges convencionals que defineixen el tipus iconogràfic conceptual de Llull. En segon lloc, dos gravats, el significat dels quals és interpretat en relació amb el context de l'època.

PARAULES CLAUS: Ramon Llull; Francesc Rosselló; edicions lul·lianes; iconografia lul·liana. 
A les edicions lul-lianes franceses, barcelonines, valencianes, i mallorquines es representen nombroses imatges de Ramon Llull. El tipus iconogràfic conceptual del savi mallorquí i els episodis de la seva vida llegendària són les imatges més abundants, i moltes d'aquestes xilografies es caracteritzen per la seva senzillesa, el to popular i planer.

En canvi, un altre grup d'imatges molt més elaborades són les anomenades estampes fines, calcografies signades per Francesc Rosselló, Llorenç Muntaner, Albert Borguny i altres, els quals aporten una millor qualitat, no sols pel tractament i la tècnica, sinó també pel seu contingut més elevat, instruït i amb un significat profund relacionat amb el context de l'època.

Tant en uns gravats com en altres, per fer més clarificador i entenedor el contingut de les imatges, es fan servir diferents tipus d'inscripcions. En alguns, un recurs freqüent és la incorporació d'un text disposat, sovint, a la part inferior que relata una breu biografia del beat. D'altres gravats s'inclou el títol de l'obra i fa la funció de portadella del llibre. Una altra fórmula usual són els tituli, molts d'ells a manera de filacteri que surten de les boques dels personatges, i d'altres situats devora els elements de caire simbòlic i revestits d'un significat concret; establint-se, doncs, una relació de text i imatge. En definitiva tots aquests recursos faciliten la correcta lectura i interpretació del significat.

\section{LA CODIFICACIÓ DEL TIPUS ICONOGRÀFIC CONCEPTUAL}

Les primeres imatges que representen la figura de Ramon Llull es forgen als manuscrits de la primera generació que abraça els segles XIV i XV. A les dotze làmines miniades que il-lustren el Breviculum, realitzades en els anys de 1321 i 1336, s'estableix el tipus visual del savi mallorquí i els episodis més rellevants que tracten la seva vida. Les primeres edicions lul-lianes recullen aquest tipus iconogràfic de Llull establert per primer cop als manuscrits. És al Llibre dels Articles de la fe o Liber Apostrophe de Pere Posa de 1504 editat a Barcelona [fig. 1] on podem veure la imatge de Ramon Llull com a mestre il-luminat, emmarcat en un rectangle a la part inferior, es representa una trama geomètrica que simula un enrajolat. Dret es presenta la figura del beat cofat i amb un hàbit semblant al de l'orde de sant Antoni, sosté un llibre obert, i alça la mirada cap al cel en el qual apareix un feix de raigs i un colom que simbolitza l'Esperit Sant. Els mots amb lletra gòtica APOSTROPHE: RAYMUNDI es retolen indicant el títol de l'obra i l'autor.

Al llarg dels segles XVII i XVIII el tipus de Llull com a mestre il-luminat és reemplaçat pel de Llull com a doctor il-luminat. Els gravats, com les pintures, mostren la faceta de Ramon com a sant escriptor vestit amb l'hàbit de terciari, amb capa, cordó nuat i roser penjat, amb barba i corona de raigs, escriu la seva obra gràcies a la inspiració divina.

Altres imatges conservades de Llull a l'àmbit mallorquí com a sant escriptor les trobem a gravats de finals de segle XVII. Un dels primers gravats conservats a la Biblioteca Lluís Alemany de Palma que coneixem segurament es degué realitzar a finals de segle XVII i s'incorporà més tard per il-lustrar un sermó de Mariano Mauro Risón de 1713 editat a Mallorca [fig. 2]. La xilografia maldestra i descuidada només s'ha treballat amb un sistema lineal, representa en una orla rectangular trenada el retrat de Llull de mig cos, porta els seus 
atributs habituals, vestit amb hàbit i capa de franciscà barbat i amb una gran corona de raigs. El seu rostre vist de perfil manté la mirada alta exclamant els mots $O$ bonitas fruit de la visió del crucifix disposat entre núvols i vora un feix de llum a l'angle dret. A les mans porta els atributs propis del sant escriptor il-luminat per Jesús crucificat, la ploma i el llibre obert amb una de les figures de la seva Art que reforcen la idea de revelació divina (Sacarès: 2014, 27).

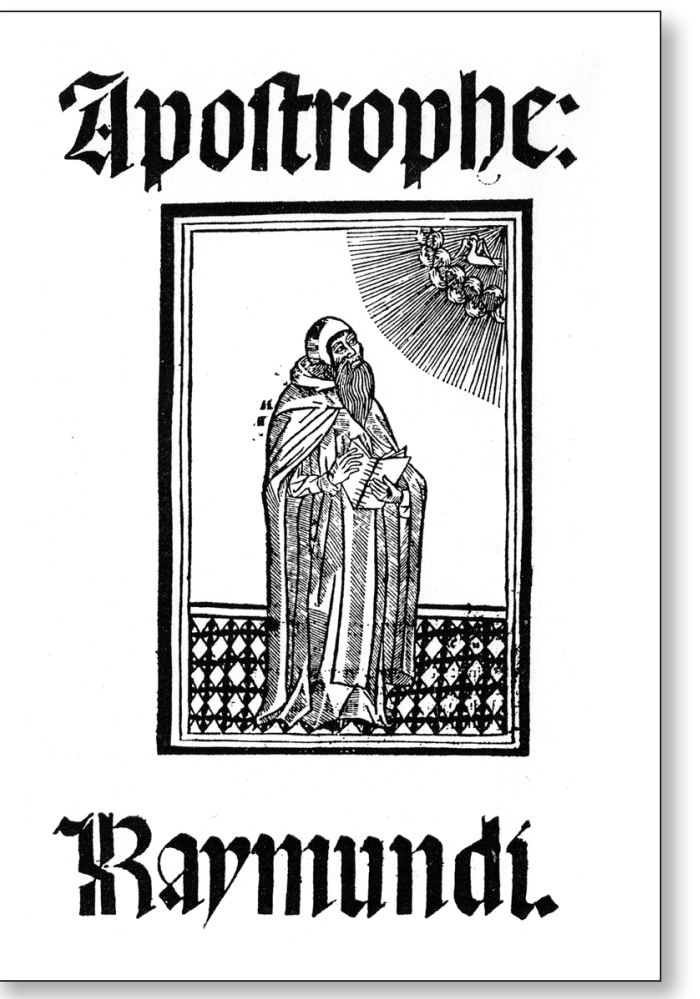

Fig. 1. Ramon Llull com a mestre il-luminat, gravat que il-lustra el Llibre dels articles de la fe o liber Apostrophe de Pere Posa, 1504, Barcelona.

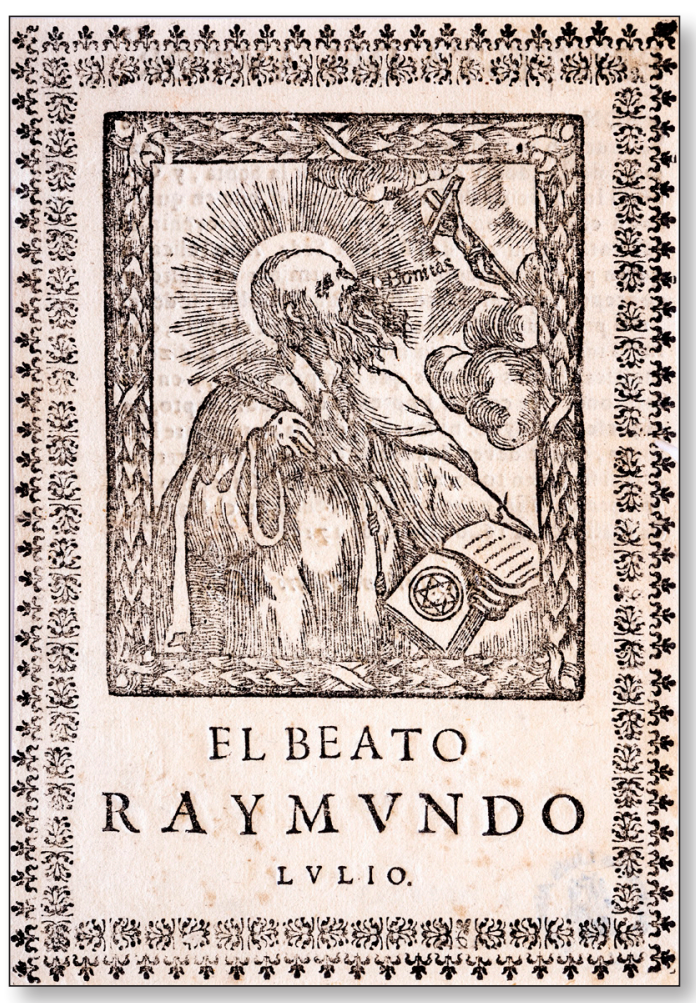

Fig. 2. Ramon Llull com a sant escriptor, sermó de Mariano Risón, 1713, Biblioteca Lluís Alemany. Palma.

\section{EPISODIS LLEGENDARIS: LA IL·LUMINACIÓ I EL MARTIRI}

Les edicions lul-lianes franceses ja des d'un primer moment incorporaren imatges de Ramon Llull. Les primeres xilografies de finals de segle XV i del segle XVI representen a Ramon com a místic contemplatiu, agenollat en un paisatge vora el mar i amb un petit crucifix.

A partir del segle XVII comencem a trobar imatges de Ramon com a místic contemplatiu però amb una aurèola circular semblant a la que porten els sants. La làmina signada per Spirinx [fig. 3] és un dels primers exemples d'aquest tipus iconogràfic. 


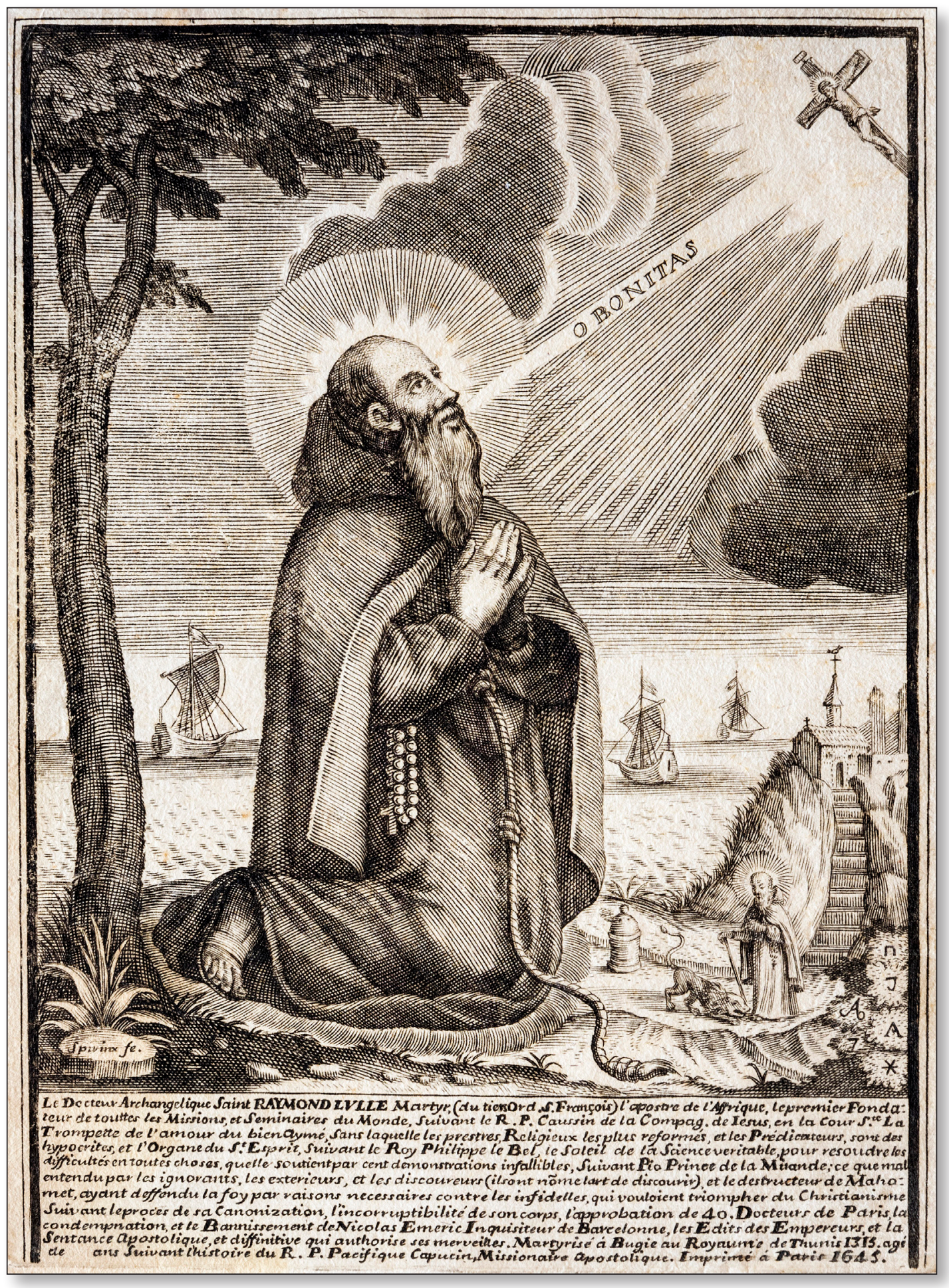

Fig. 3 Ramon Llull com a místic contemplatiu, calcografia de Louis Spirinx, 1675. Biblioteca Lluís Alemany, Palma. 
L'autor pertany al llinatge de gravadors que foren actius al llarg dels segles XVI i XVII a la ciutat de Lió. Per les correspondències de les dates podem deduir que el gravat degué esser obra de Louis Spirinx, nascut a Anvers l'any 1596 i mort a 1669 a Lió.

La representació molt acurada segueix un model semblant als esmentats anteriorment. Llull aquí apareix amb indumentària caputxina, capa curta i caputxó, i a la cintura cordó nuat i roser penjat. A diferència de les anteriors imatges, és representat amb una gran aurèola. El cercle lluminós es relaciona amb la llegenda que apareix al peu del gravat: $L e$ Docteur Archangelique saint Raymond Lulle martyr, seguida d'una breu biografia manllevada del caputxí Pacífic de Provins. El títol de sant concedit pels francesos justifica el nimbe circular, símbol de perfecció i santedat.

El gravat francès evoca l'ideal místic del mateix Llull, les escenes del vell ermità ascètic, auster i benigne retirat als frondosos boscs, i ocupant-se de la lectura i la contemplació, són reiteratives a l'opus lul-lià, amb no pocs tints autobiogràfics.

El recer d'un arbre com a lloc predilecte per fer oració és un topos en l'obra de Llull, com ara al Blaquerna, de manera semblant, el gravat transcriu els paratges lul-lians. El Beat rep l'experiència mística, al resguard de l'arbre, la proximitat del mar acapara el paisatge de fons, l'ermita elevada és accessible per una graonada, l'episodi es completa amb una altra escena lligada amb la temàtica dels solitaris del desert, l'encontre de Llull i el lleó (Sacarès: 2007-2008, 109).

El gravat de Miquel Capó imprès l'any 1700 a la portada de Disertaciones Históricas de Jaume Custurer, és tal volta l'exemple paradigmàtic que plasma la nova tipologia iconogràfica del Doctor Il-luminat. Reflecteix l'evolució de l'escena, ara Ramon agenollat ploma en mà, escriu els llibres sobre un penyal, atenent a les paraules que sembla dictar-li el crucificat. Per tant la seva obra és fruit de la intel-ligència il-luminada i de la revelació divina, i es palesa a la seva tipologia iconogràfica mitjançant el llibre obert i la ploma, eina amb la qual li permet escriure la seva obra i és atribut de saviesa i de doctor.

A més l'escena de Randa es nodrí amb elements procedents de les llegendes pròpies de Mallorca, l'episodi de la mata escrita ja es recollit a la biografia de l'humanista Charles de Bouvelles (Sollerio, 1708: 39). El llentiscle present en l'aparició de Jesús crucificat el qual romangué escrit desprès de la revelació amb caràcters de diferents llengües per abastar un major nombre de fidels la seva Art.

En el gravat a la dreta hi és present la mata prodigiosa, testimoni de la il-luminació i uns mots que identifiquen l'element devocionari: Dumus scriptus prodigiosus viret, i a l'angle superior l'àngel anunciador fa sonar la trompeta, de la qual surt la llegenda: Dei molemque canimusque Palmam.

El gravat tingué vigència al llarg del segle XVIII. Diverses edicions dedicades a l'obra de Llull, empraren el gravat per il-lustrar les primeres pàgines, però amb una observació acurada ens adonem que hi hagué fins a tres versions diferents.

La versió més arcaica i senzilla és la que apareix a la portada de Opera Parva de Pere Antoni Capó de l'any 1746. A primera vista veiem la signatura del gravador al peu del gravat Capó F., inexistent a les altres dues representacions, en canvi alguns detalls s'han obviat com ara la llegenda de la mata és incompleta, la fisonomia de l’àngel i el Beat no està tan treballada, el traç és lineal i més gruixut sense tonalitats. En canvi, el gravat [fig. 4] que es troba al llibre de J. B Sollerio es veu un treball molt més minuciós i un gust pel detall, fruit del treball al burí, l'habilitat per traçar línies més fines i un domini de l'ombratge a les robes del Beat palesen la qualitat de la composició. 


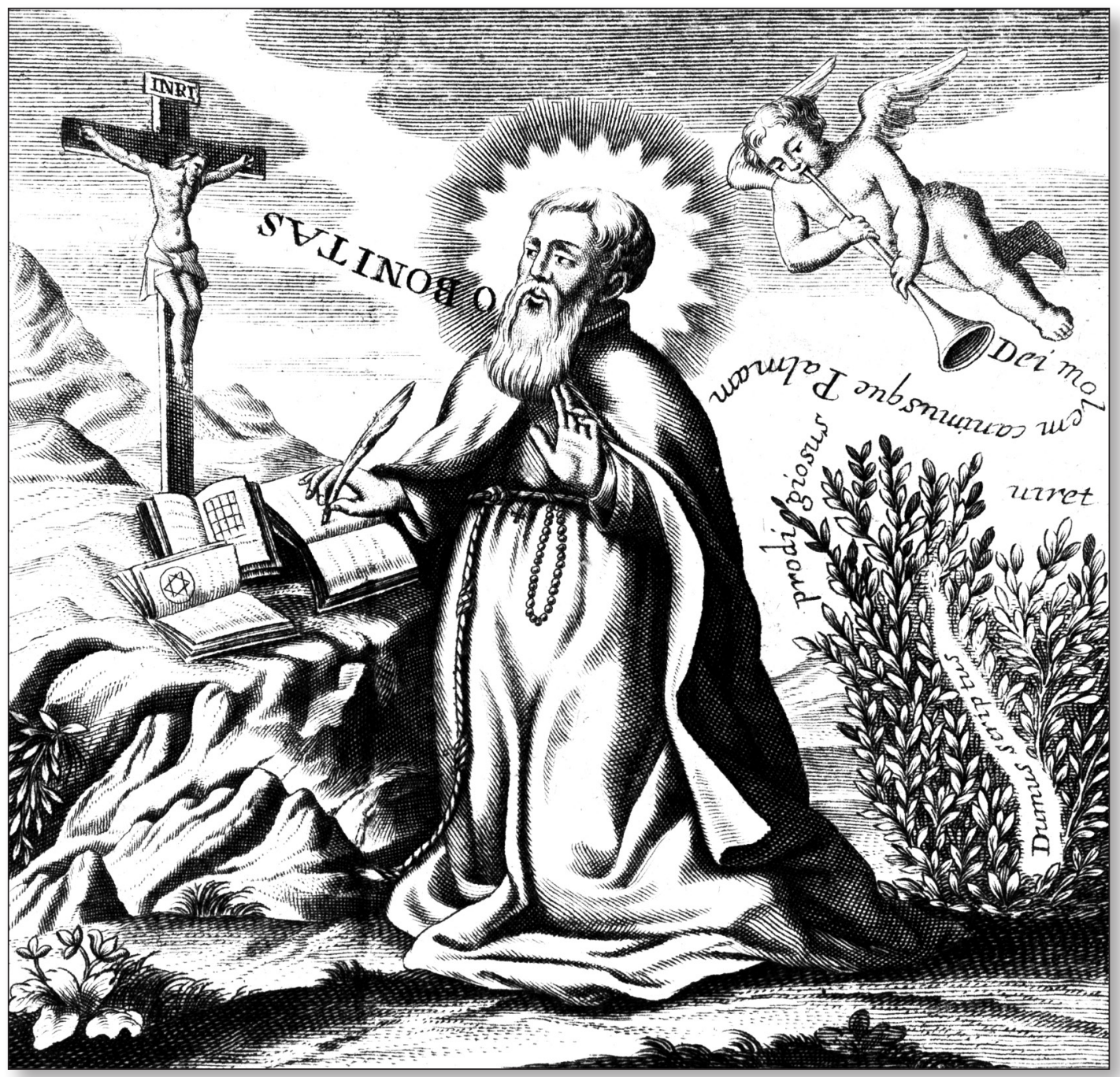

Fig. 4. Ramon Llull com a doctor il-luminat, calcografia que il-lustra l'Acta B. Raymundi Lulli de J. B. Solliero de 1708.

El tractament del rostre del Beat i de l'àngel ha guanyat nitidesa. Crida l'atenció el Crist crucificat, que a les anteriors xilografies era un Crist mort, en aquesta calcografia se'ns mostra proper al Crist triomfant (Reau, 1997: 445-446), dirigint la mirada cap el Beat, com si li parlés.

En el decurs dels segles XVII i XVIII es desenvolupa el tema martirial. Les fonts utilitzades per a la creació d’aquesta visualitat són diverses, d'una banda l'associació amb la lapidació de sant Esteve és clara. La ciutat emmurallada al fons amb el diaca agenollat en acte de pregària suporta la pluja de pedres llançades pels botxins, i des de l'àmbit celestial se li entrega al màrtir la corona que honora el seu nom. Són trets bàsics traslladats amb exactitud a l'episodi martirial del Beat. Una bona mostra d'aquesta derivació és el gravat de Melcior Guasp datat l'any 1755. Aquest tipus de composició va servir de model per a diversos llenços destinats a retaules que es troben a algunes esglésies mallorquines (Sacarès, 2006: 92). 
El gravat popular del segle XVII [fig. 5] publicat per primera vegada a un llibre de Pere Bennàsser (Bennàsser, 1688: 90) de la imprenta Guasp l'any 1688 és reiterat posteriorment de manera semblant a la col-lecció de xilografies mallorquines de la impremta Guasp. La xilografia signada amb les inicials RO, pertany al gravador Francesc Rosselló (Furió, 1859: 236-239). Es tracta ja no d'un tipus conceptual, com hem vist fins ara, sinó plenament narratiu. Es manté una primacia per il-lustrar el paisatge, el topònim de la ciutat perquè no hi hagi dubtes és retolat a la part superior de la població, tot recordant els primers gravats. Més enllà es dibuixa la mar amb la nau que se'n portarà el cos de Llull, aquest es troba davant un arbrissó, mentre quatre moros el lapiden, sota l'atenta vigilància del comandant. En segon terme apareix una comitiva a prop d'un pou que sembla que llancen un personatge. La incògnita d'aquesta comitiva i el pou ja era advertida per Gabriel Llompart (Llompart, 1982: 13-17). Només podem insinuar que es tracti de la claveguera de la qual parlen les biografies, allà on fou llançat i se li proposà renegar de la fe cristiana.

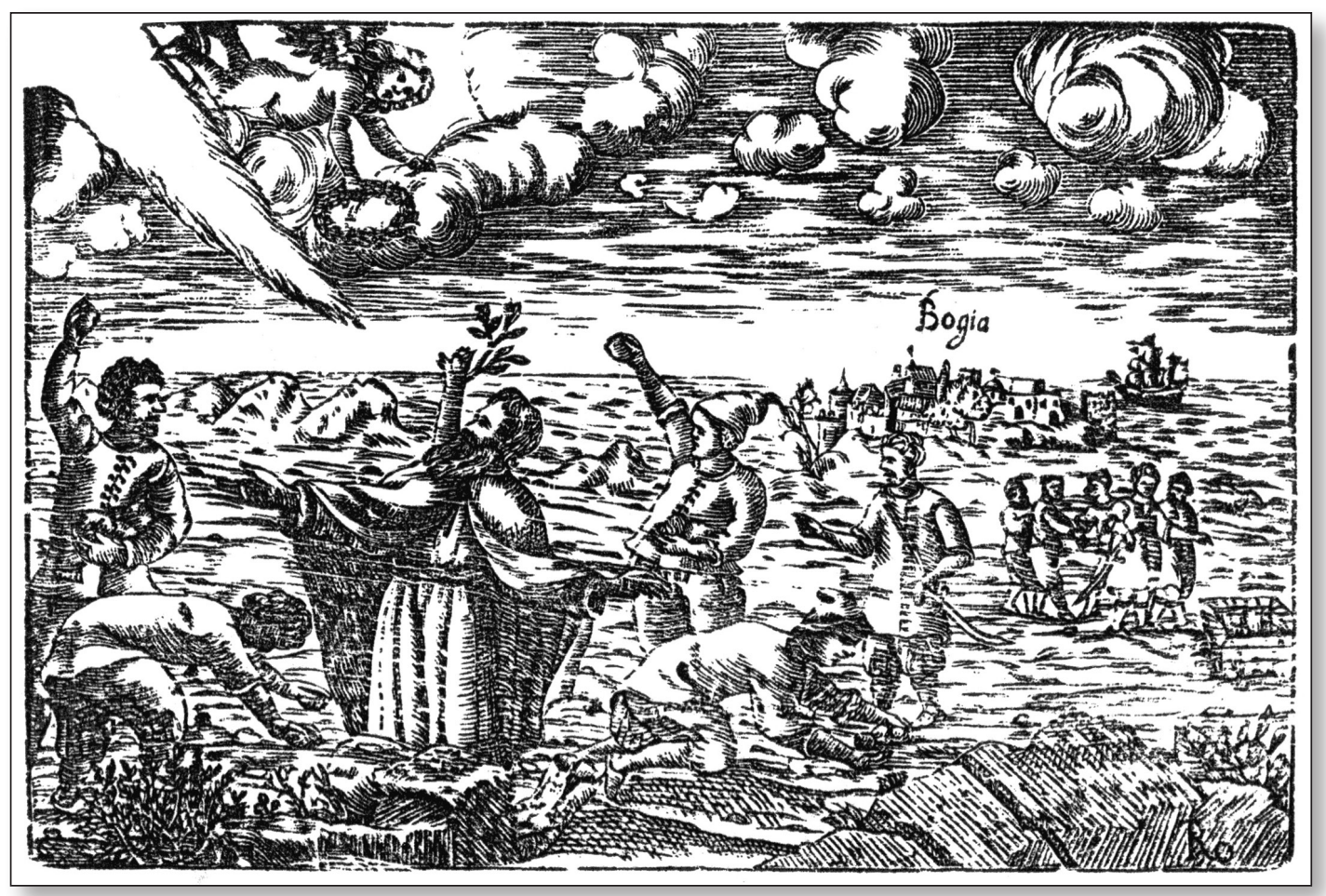

Fig. 5. Martiri de Ramon Llull, xilografia de Francesc Rosselló, 1688, col·lecció Guasp.

\section{ELS GRAVATS EXCEPCIONALS I ELS SEUS MISSATGES}

L'anglès Charles Toll Bidwell, cònsol de la reina Victòria d'Anglaterra, viatjà a Mallorca als anys 1868 i 1875. Durant la seva estada a l'illa, a més de realitzar la seva tasca diplomàtica, recopilà una informació variada que publicà com a llibret de viatges anomenat The Balearic Island i editat a Londres l'any 1876. Es refereix a Antoni Furió per recordar el paper transcendental de Francesc Rosselló en la introducció de la calcografia a l'illa. Va escriure:

IMAGO, NÚM. 8, 2016, I43-I53 


\begin{abstract}
Nosaltres mateixos recuperàrem a una vella tenda de coses curioses de Palma, un gravat de grans mides d'aquest artista que representa el paradís amb Adam i Eva, i molts de tipus d'animals, ocells, etc. L'arbre de ciència del bé i del mal es troba al centre a la capçada del qual descansa la Mare de Déu. Als peus de l'arbre hi ha l'escut d'armes de la família Sureda, marquès de Vivot. $\mathrm{Al}$ primer pla, es troben els quatre doctors reconeguts per la seva defensa de la doctrina de la Immaculada Concepció, sant Gregori, sant Bonaventura, el beat Ramon Llull, i el venerable Duns Escot. Que semblin que mullin les plomes als quatre rius del paradís plomes amb les quals escriuen el seu text que cadascun sosté amb les mans, i que és al-lusiu al miracle que defensen, que més tard es va convertir en dogma de l'església catòlica. Aquest gravat, que es ben curiós i no mancat de mèrit artístic duu la següent inscripció rosselló delinn, et excusit , 1671, in tempore tribulationis. (Bidwell, 1997: 185)
\end{abstract}

És ben singular que un diplomàtic poc conegut del segle XIX s'interessés per un gravat mallorquí del segle XVII en el qual precisament es representa la figura de Ramon Llull i intenti treure l'entrellat iconogràfic. La qualitat de la calcografia de grans dimensions del gravador Francesc Rosselló [fig. 6], especialista en gravats de temàtica lul-liana, no va passar desapercebuda pel cònsol britànic, i sembla evident la importància que li va donar.

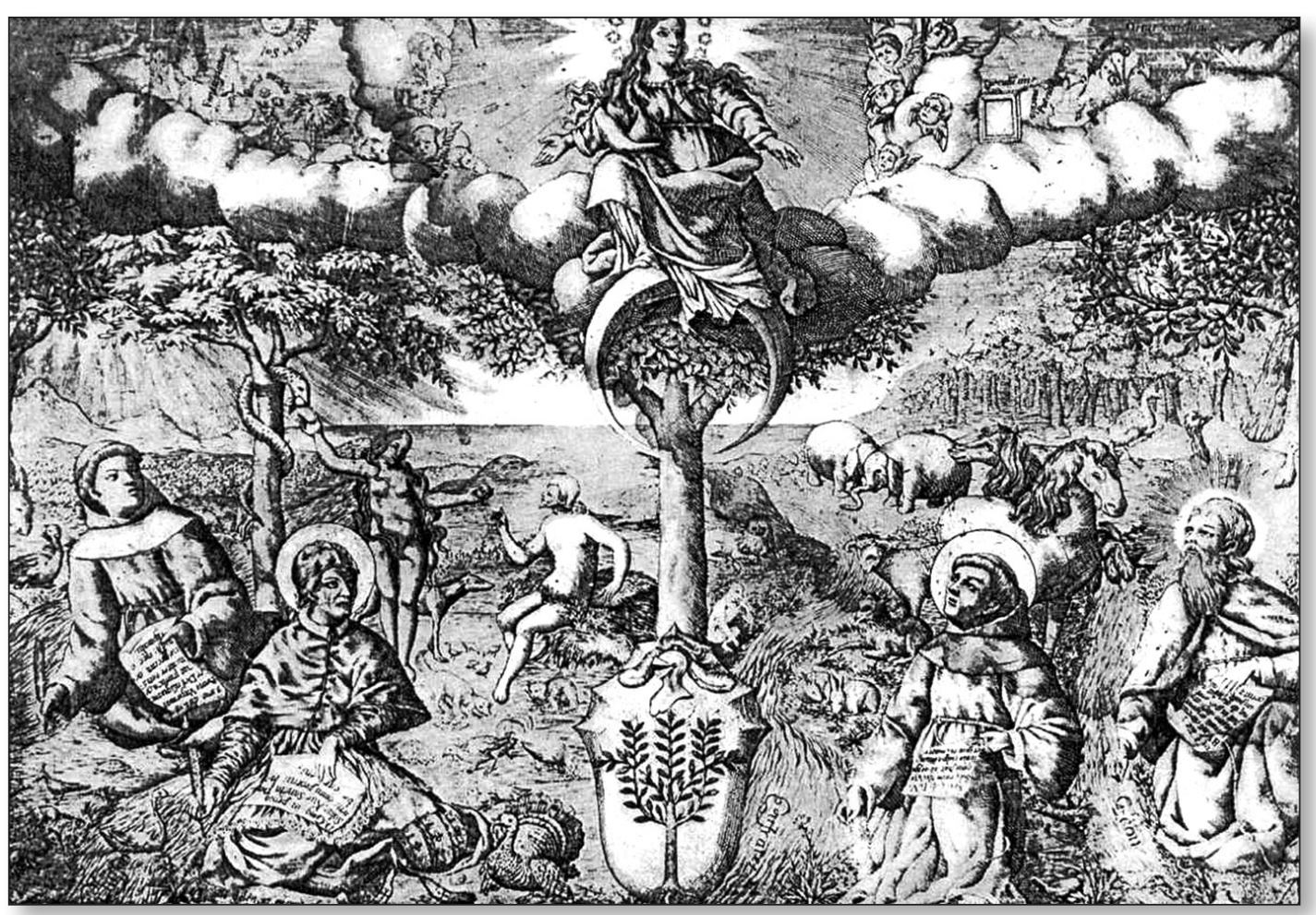

Fig. 6. Al-legoria de la defensa de la Immaculada, calcografia, Francesc Rosselló, 1671, Biblioteca Lluís Alemany, Palma.

La calcografia de grans dimensions de Francesc Rosselló, datada l'any 1671, és una excepció dins el conjunt d'estampes que veurem entre d'altres coses pel grup de personatges que agrupa i pel seu interés iconogràfic. 
A l'estampa es recrea el paradís terrenal, al centre es disposa l’arbre del bé i del mal i sobre la copa roman la figura de la Immaculada, trepitjant la mitja lluna, un seguit de núvols amb els atributs de la Puríssima: sol, lluna, font, mirall, palmera i les seves corresponents inscripcions realcen el firmament. A l'àmbit terrenal, a l'arrel de l'arbre es dibuixa l'escut dels Sureda, marquesos de Vivot. A cada costat, i en primer terme es representen Sant Bonaventura, i Sant Gregori, tots dos amb nimbe circular; en segon terme el venerable Escot i el beat Ramon Llull. Els quatre doctors mullen les seves plomes en els quatre rius del paradís, els quals estan també rubricats devora: Tigris, Phison, Eufrates, i Geon; i escriuen la seva obra en el pergamí que sostenen amb l'altra mà també amb text escrit. En un pla més llunyà es representa el paradís amb tota varietat d'animals i l'escena d’Adam i Eva que prenen el fruit prohibit ofert per la serp que està enroscada a l'arbre.

La Immaculada Concepció és sens dubte el tema de l'estampa, la incorporació de la figura de Sant Gregori, també com a escriptor marià intensifica la supremacia de la Immaculada, a més la visió del paradís amb l'escena d’Adam i Eva manifesta l'episodi del pecat original, i l'exempció de la Puríssima. Aquí la Puríssima assoleix el paper de la dona del Gènesi, la nova Eva. Un altre element que cal tenir present és l'escut de la família noble dels Sureda, marquesos de Vivot, en aquest cas l'hem d'entendre com a avaladora, i també promotora del privilegi de Maria. Una altra qüestió per a destacar és la signatura que apareix a l'inferior: Rosselló delin et excusit 1671 in tempore tribulationis (Quiroga, 2014: 36).

De fet, la làmina va esser descrita i ressenyada per Antoni Furió, (Furió, 1859: 146-147) el qual aportava valuosa informació sobre el discurs visual, o millor dit el context en què va esser creada la calcografia. L'acadèmic relatava que la causa de dita aflicció o patiment, inscrit per Rosselló, era l'escàndol que en aquell any s'originà a la diòcesi mallorquina. Resulta que en aquells dies va esser nomenat canonge el senyor Diego Desclapés, el Capítol acordà a no assistir a cap festa oficiada per aquest canonge, pel fet de no comptar amb mèrits suficients. Desclapés que era consultor de la Inquisició presentà les seves queixes a l'inquisidor major, don Bartolomé del Prado, el qual sense tenir facultats pròpies al seu ofici, revocà i manà al Capítol dia 3 de juny d'aquell any, que sota pena d’excomunicació anulàs la resolució adoptada de no assistir als actes oficiats per Desclapés en el termini de tres dies, cosa que el Capítol no acceptà ni complí. Llavors, l'ínquisidor excomunicà al Capítol, el qual respongué amb les mateixes armes i excomunicà a l'inquisidor general. Els decrets es publicaren a les parròquies i als convents $i$, provocà tal revolta en el poble mallorquí, que śapel-là a Roma per solucionar el conflicte. A l'església de santa Maria de la Minerva, en una congregació formada per la Inquisició General s'acordà que l'ínquisidor s'havia excedit en les seves funcions i, que havia obrat sense facultats i de manera arbitrària; i en conseqüència eren nul-les les seves excomunicacions. Jeroni Juan Tous (Juan, 1977: 23) recollia el relat i assegurava que era aquest assumpte, el qual es referia l'autor del gravat, però, també apuntava un altre motiu que era suposat per altres, hi era l'epidèmia de pesta que assolà Palma i causà gran mortalitat. Tanmateix, aquesta darrera causa esmentada sembla poc probable ja que el brot de pesta més fort fou l'any 1652 (Casanova, 1986: 51-62), hi ha una distància considerable amb la data del gravat.

Sigui com sigui aquest temps d'aflicció o patiment a què fa referència el gravador, està lligat en el marc de les controvèrsies de la Immaculada. El contingut temàtic forma part del conjunt d'imatges destinades a la preservació i culte de la Immaculada dels segles XVII i XVIII.

Un gravat que guarda semblances amb el repertori iconogràfic del retaule de la capella «nova» del beat Ramon és el que es reproduí al primer volum del Bolletí de la Societat Arque- 
ològica. A la làmina [fig. 7] es representa en un medalló decorat per volutes i fulles de llorer i sostingut per dos àngels el retrat del canonge Llull, porta capa i birret doctoral, les faccions del rostre corresponen als distints retrats que es coneixen del canonge, front alt, nas aguilenc, i barba. A la part inferior, una carassa amb fistons de fruita forma un escut en el qual s'hi dibuixa la mitja lluna símbol del llinatge de Llull. A la part superior del medalló apareix el cap d'un àngel en el qual s'hi assenta el grup format per la Mare de Déu amb una mà porta un llibre obert i amb l'altra sosté el nin Jesús, i al seu costat Llull que agenollat li besa els peus. A terra devora el Beat el llibre obert escrit. La representació s'emmarca per una arquitectura arquitravada i coronada per dues piràmides que prenen forma d'obeliscs. Dues personificacions al-legòriques femenines decoren i flanquegen la composició: a l'esquerra molt possiblement la geometria o l'astronomia amb la bolla del món i el compàs, i a la dreta la filosofia o bé la teologia amb el ceptre i el pergamí escrit com atributs. El gravat presenta una disposició icònica amb un contingut que exalta les qualitats del canonge Llull com a home il-lustrat per la seva ciència i virtut, la inscripció del filacteri ho indica: Ac per illustri domino D. Bartho lull canonico Poenitent. Les dues al-legories de les arts liberals fan referència a les ciències que cultivà, els obeliscs transmeten la idea del raig de llum, símbol de saviesa, a la part superior la Mare de Déu i l'infant Jesús amb Ramon Llull, remarquen el sentit del Col-legi creat com a centre de saviesa i amb la petja del Doctor il-luminat: Sapientia edificat sibi domun Pro. En definitiva, intel-ligència privilegiada, il-lustrat talent, criteri pràctic, i de cor noble i caritatiu va ser el canonge Bartomeu Llull fundador de la Sapiència.

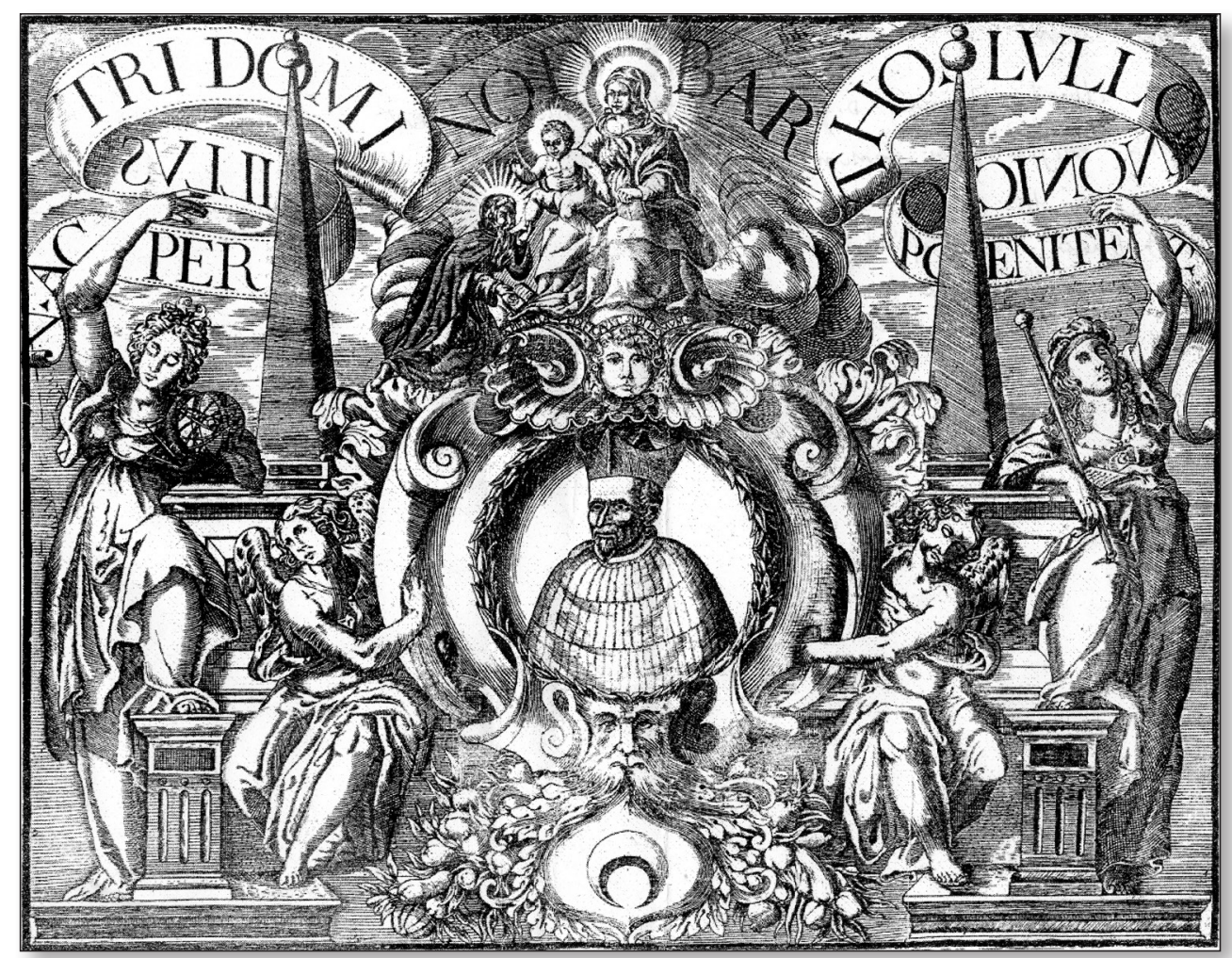

Fig. 7. Calcografia dedicada al canonge Bartomeu Llull, primer quart de segle XVIII, atribuïda a Llorenç Vallespir. 
Juan Lladó apuntava que el gravat era un modest, però, significatiu record que el Col-legi de la Sapiència tributà al seu il-lustre fundador Don Bartomeu Llull, afegint que la làmina degué gravar-se en plena època del "xurrigueresc», no de bades en desencert opinava que l'incorrecte dibuix dominava i que les figures accessòries preocupaven més a l'autor que la principal, (Lladó, 1885: 7-8).

Les característiques formals i estilístiques del gravat permeten datar-lo del primer quart del segle XVIII, és més tenim motius per pensar que la làmina fou realitzada per Llorenç Vallespir. L'atribució la podem fonamentar mitjançant les figures, les quals són perfectament recognoscibles: rostres allargats, front pla, i ulls petits i ametllats. A més a més la decoració característica de marcs florals en negatiu n'és una altra prova. Tanmateix hem de recordar que Vallespir dedicà nombrosos gravats de temàtica lul-liana, l'admiració que devia sentir per Ramon Llull -segons consta en el seu testament en poder del notari Pere Antoni Colom, redactat el 19 de setembre de 1728 - li valgué elegir sepultura davant la capella del beat Ramon Llull en el convent de sant Francesc d'Assís.

\section{BIBLIOGRAFIA}

Bennàssar, P. [1691]. Causa pía de R. Lullio, al rey nuestro señor D. Carlos Segundo, Guasp, Mallorca.

- [1699]. Breve ac compendiosum rescriptum navitatem, vitam martyrium cultum immemorabilem pii heremitae ac venerabilis martyris Raymundi Lulli, Mallorca.

Bidwell, Ch. Toll, [1997], Les illes Balears, Lleonard Muntaner, col. Llibres de viatges, núm. 1, Palma, (1876).

Bouvelles, de Ch. [1708], «Epistola in vitam Raemundi eremitae» en J. B. Sollerio, Acta B. Raymundi Lulli, Anvers.

Bover, J. M. [1983]. Nobiliario mallorquín, Palma, J.J. de Olañeta.

FortezA, M. [2007]. La xilografía en Mallorca a través de sus colecciones. La imprenta Guasp (15761958), Palma, J.J de Olañeta.

JuAn Tous, J. [1977]. Grabadores mallorquines, Instituto de Estudios Baleáricos, Palma,

Junyent, E. [1935]. «El cicle concepcionista de la Seu de Barcelona», Analecta Sacra Tarraconensia, núm. 11.

LLADÓ, J. [1885-1886]. «Bartolomé Lull», BSAL, t. I, p.7-8.

Llompart, G. [1982]. "Moros vénen, un tema secular de l'ex-vot pintat balear», Lluc, núm 704, p. 13-17.

Quiroga, de M. [2014], «In tempore tribulationis (grabado mallorquín de Francesc Rosselló 1671 ", Memòries de la Reial Acadèmia Mallorquina d'Estudis Geneaològics, Heràldics i Històrics, núm.24, 33-54.

RÉAU, L. [1997], Iconografia del arte cristiano, Barcelona, (1937), t,. 1, vol. 2.

SACARÈs Miquela, [2006], Il-luminació i martiri: introducció a la iconografia de Ramon Llull, treball de recerca, Departament d'Art. Universitat Autònoma de Barcelona.

- [2007-2008], «"En un instant li venc certa il·lustració divinal» L'episodi de la il·luminació a la iconografia de Ramon Llull», Locus Amoenus, núm.9, 2007-2008, Universitat Autònoma de Barcelona.

- [2016] Vivat ars lulliana. Ramon Llull i la seva iconografia, Palma, J. de Olañeta. 
